\title{
Adapting to the Cold: A Role for Endogenous Fibroblast Growth Factor 21 in Thermoregulation?
}

\author{
Marlou Klein Hazebroek and Susanne Keipert* \\ Department of Molecular Biosciences, The Wenner-Gren Institute, Stockholm University, Stockholm, Sweden
}

Fibroblast growth factor 21 (FGF21) is in biomedical focus as a treatment option for metabolic diseases, given that administration improves metabolism in mice and humans. The metabolic effects of exogenous FGF21 administration are well-characterized, but the physiological role of endogenous FGF21 has not been fully understood yet. Despite cold-induced FGF21 expression and increased circulating levels in some studies, which co-occur with brown fat thermogenesis, recent studies in cold-acclimated mice demonstrate the dispensability of FGF21 for maintenance of body temperature, thereby questioning FGF21's role for thermogenesis. Here we discuss the evidence either supporting or opposing the role of endogenous FGF21 for thermogenesis based on the current literature. FGF21, secreted by brown fat or liver, is likely not required for energy homeostasis in the cold, but the nutritional conditions could modulate the interaction between FGF21, energy metabolism, and thermoregulation.

\section{OPEN ACCESS}

Edited by:

Colin Selman,

University of Glasgow

United Kingdom

Reviewed by:

Marianna Sadagurski,

Wayne State University, United States

Xinran $\mathrm{Ma}$

East China Normal University, China

*Correspondence:

Susanne Keipert

susanne.keipert@su.se

Specialty section: This article was submitted to Endocrinology of Aging, a section of the journal Frontiers in Endocrinology

Received: 05 April 2020 Accepted: 15 May 2020 Published: 02 July 2020

Citation: Klein Hazebroek $M$ and Keipert S (2020) Adapting to the Cold: A Role

for Endogenous Fibroblast Growth

Factor 21 in Thermoregulation?

Front. Endocrinol. 11:389.

doi: 10.3389/fendo.2020.00389
Keywords: cold exposure, brown adipose tissue, beige adipose tissue, uncoupling protein 1, endocrine signaling, low protein diet, energy metabolism

\section{INTRODUCTION}

The ability to combat cold stress is crucial for the survival of mammals. Especially in small rodents and human infants, brown adipose tissue (BAT) and its unique protein uncoupling protein 1 (UCP1) play an important role in the maintenance of core body temperature (1). When activated, UCP1 uncouples mitochondrial respiration from ATP production, resulting in the direct dissipation of oxidative energy as heat (2). The expression of UCP1 is not restricted to BAT. UCP1 can be recruited in white adipose tissue (WAT), classifying it as beige adipose tissue, through various stimuli, i.e., cold exposure, beta-adrenergic stimulation, and various peripheral signals. One of these peripheral signals is endocrine-acting metabolic regulator fibroblast growth factor 21 (FGF21).

It has been well-documented that the pharmacological administration of FGF21 and its analogs improves the metabolic profiles in mice and humans by decreasing adiposity, serum lipids, and blood glucose levels (3-7). Furthermore, the administration of FGF21 increases energy expenditure (7) and potently stimulates beige adipose tissue $(8,9)$. Its efficacy in humans promoted the interest in FGF21 as a promising therapeutic molecule for various metabolic diseases (e.g., obesity, type 2 diabetes, and non-alcoholic fatty liver disease). Therefore, it is not surprising that several clinical trials using FGF21 analogs have already reached phase $2(10,11)$ and are under investigation to enter phase 3 (12). On the other hand, the role of endogenous FGF21 is less established. Endogenous FGF21 is regulated upon cold exposure in mice (see, for an overview of references, Figure 1), and a growing number of publications indicate the regulation of circulating FGF21 in response to cold in humans (15-17). 

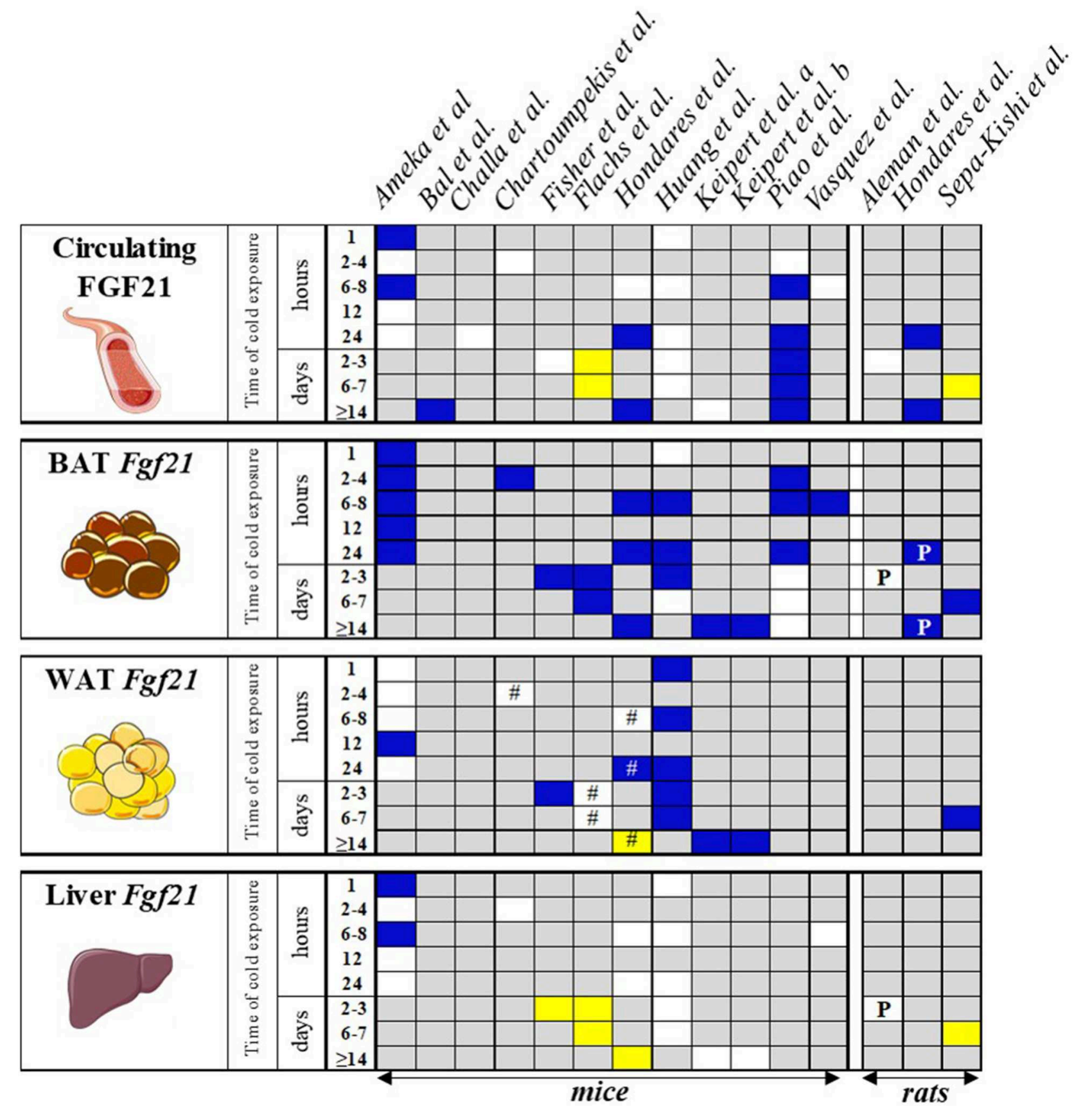

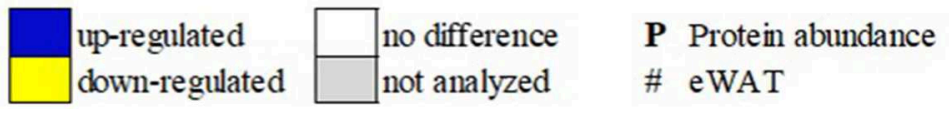

FIGURE 1 | Schematic overview of publications investigating the effect of cold exposure on circulating FGF21 and Fgf21 expression levels in various tissues of the WT control mice. Blue box, FGF21 was up-regulated; yellow box, FGF21 was down-regulated; white box, FGF21 not differently regulated vs. control; gray box, not analyzed. The data represent circulating levels and mRNA expression, unless otherwise specified. WAT, white adipose tissue (subcutaneous unless otherwise stated); BAT, brown adipose tissue. Keipert et al. a (13), b (14). Parts of this cartoon were created using Servier Medical Art (http://smart.servier.com).

Clarifying the underlying mechanisms of changes in endogenous levels upon cold is challenging because FGF21 can be secreted from various tissues, contributing to the serum concentration (18). So far, verifying the origin of FGF21 secretion in humans has been complicated. Although cold exposure is known to stimulate FGF21 expression in both 
humans and animal models, its metabolic consequence in thermogenically competent adipose tissue during cold remains incompletely understood. In this review, we will concentrate on the physiological role of endogenous FGF21 upon cold exposure and FGF21's metabolic effects, focusing on its importance in thermoregulation and metabolic homeostasis.

\section{FGF21'S TISSUE SPECIFICITY AND REGULATION}

FGF21 and its relatives, FGF15/19 and FGF23, are atypical members of the FGF family based on their role as endocrine factors (19). After synthesis and secretion, FGF21 acts as a circulating hormone that binds to fibroblast growth factor receptors and cofactor $\beta$-Klotho to form a ternary complex, which is responsible for FGF21 specificity and required to induce signal transduction in target tissues (20-23). The liver has been considered as the major source of circulating FGF21 in adult mice (24). Besides the liver, however, FGF21 is also synthesized in several other tissues, including the pancreas (25), skeletal muscle (26), and adipose tissue $(13,27)$. Over the last years, the central nervous system and adipose tissue have emerged as the key target organs of FGF21 action in improving metabolism $(3,28-30)$. For example, the insulin-sensitizing effects of FGF21 in mice are primarily regulated by adipose tissue (28), whereas the effects on energy expenditure and weight loss are mainly regulated centrally (31). The pharmacological administration of native FGF21 in mouse and human studies induces thermogenic gene expression in WAT and BAT, for example, Ucp 1 and Dio2 (8, $9,16)$. The induction of thermogenic genes can be a direct effect on adipose tissue (9) as well as indirect by the central nervous system $(31,32)$. FGF21 administration enhances the sympathetic outflow toward adipose tissue, possibly involving the induction of corticotropin-releasing hormone (31), which in turn activates the $\beta$-adrenergic-cAMP-mediated pathway, thereby turning on Ucp1 expression. Furthermore, Fgf21 mRNA expression itself is induced in adipose tissue in response to stimulation with $\beta$-adrenergic agonists [e.g., isoproterenol; (9, 33)]. Although the pharmacological administration of FGF21 and B-adrenergic agonists indicates a function of FGF21 in thermoregulation, the question on the role of endogenous FGF21 upon cold exposure remains unanswered.

\section{IS CIRCULATING FGF21 AN ENDOCRINE METABOLIC REGULATOR UPON COLD EXPOSURE?}

A study performed in neonatal mouse pups was the first to suggest an endocrine role of endogenous FGF21 in thermoregulation (34). Here the consumption of maternal milk (i.e., initial lipid intake) triggered liver Fgf21 expression in newborn mice, leading to an increase in circulating FGF21 levels. Notably, the rise in FGF21 plasma levels parallels the thermogenic gene expression in neonatal BAT after birth. Given these results, the authors suggested a liver-FGF21-BAT axis, in which FGF21, secreted by the liver, contributes to the activation of BAT thermogenesis to defend the body temperature during early life. Although the mice were not housed at $4^{\circ} \mathrm{C}$ in this study, it inspired the idea that a liver-FGF21-BAT axis might also be present in thermogenesis in later life. Since then, many studies attempted to uncover the possible endocrine role of endogenous FGF21 upon cold exposure in adult mice, with controversial results.

Numerous studies show that circulating FGF21 is upregulated in wild-type (WT) mice housed at $4-6^{\circ} \mathrm{C}(34-38)$, while others did not observe this induction $(9,13,33,39-41)$ but instead report on a decrease [(42); Figure 1]. The inconsistencies between the studies may be explained by the differences in animal model or experimental design. However, a summary of the published data from 13 mouse and three rat studies (Table 1) reveals that gender, age, or genetic background cannot explain the differences as most of the studies used adult male mice on a C57BL/6J background or male Wistar rats. Furthermore, the housing temperature before cold treatment and the duration of the cold treatment seem to have no consistent effect on FGF21 secretion (Table 1 and Figure 1). In addition to the ambiguity of whether circulating FGF21 increases upon cold treatment, a closer inspection of the publications that observe an increase shows that there are inconsistencies concerning the tissue responsible for the secretion. Two main tissues arise, BAT and liver, which we will now discuss individually.

\section{BROWN ADIPOSE TISSUE AS THE SOURCE FOR CIRCULATING FGF21}

Hondares et al. (27) were the first to show increased circulating FGF21 levels upon cold exposure in adult mice (27). After $6 \mathrm{~h}$ at $4^{\circ} \mathrm{C}$, the circulating FGF21 levels were not different compared to those of mice kept at $30^{\circ} \mathrm{C}$, yet the mice showed increased levels after $24 \mathrm{~h}$ and 30 days at $4^{\circ} \mathrm{C}$. A gene expression analysis suggested BAT as an FGF21 source, as reflected in induced mRNA levels. In contrast, Fgf21 mRNA in the liver remained unchanged $(6 \mathrm{~h})$ or even decreased upon long-term cold exposure $(24 \mathrm{~h})$. In the same study, but using rats, in vivo arteriovenous differences in plasma FGF21 across interscapular BAT were measured, confirming the release of FGF21 from BAT (27). In 2018, others followed up on these findings, showing that the circulating FGF21 levels increase throughout $8 \mathrm{~h}$ to 14 days of cold treatment period (38). The authors claim BAT to be the source of increased FGF21 as this was associated with an early induction of Fgf21 gene expression in this tissue, which declines after 7 days. When interpreting these data, we may bear in mind that no further gene expression data of other potential FGF21 secreting tissues were included, as well as the lack of specific knock-out models. Thus, it is difficult to determine the tissue responsible for the increase in circulating FGF21. However, Piao et al. (38) showed an important role of circulating FGF21 action in the induction of WAT browning during cold acclimation (38). Neither centrally nor peripherally administered FGF21 initiated the induction of beige fat in mice lacking $\beta$-adrenoceptors, demonstrating that an intact adrenergic system is necessary for FGF21 action $(31,32)$. These data suggest FGF21 signals via 
TABLE 1 | Overview of experimental designs and study specifics of publications on FGF21 and cold exposure at 4-8 ${ }^{\circ} \mathrm{C}$.

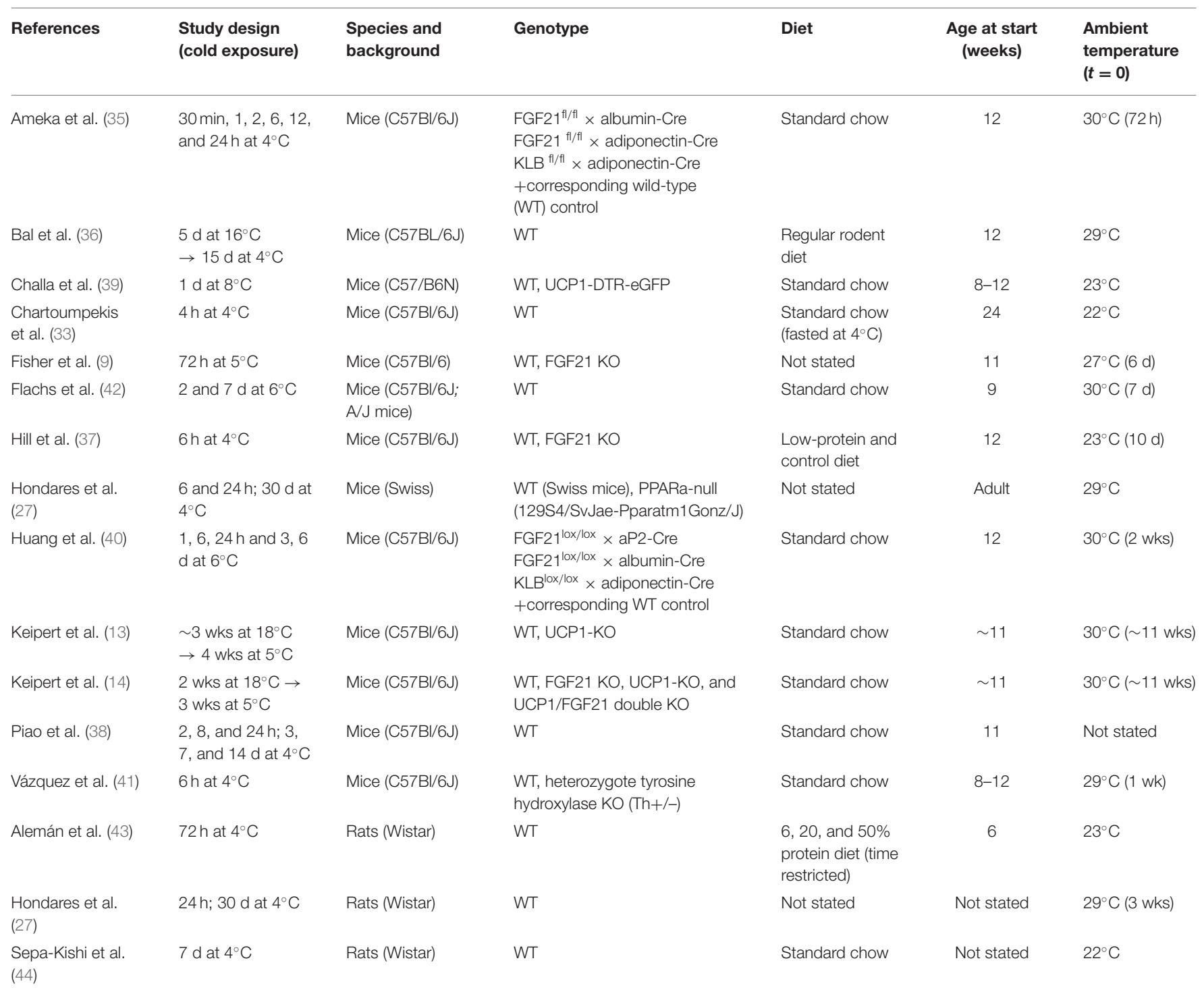

All studies used male mice and rats. $h$, hour(s); d, day(s); wk(s), week(s); $\rightarrow$ "followed by".

the brain to activate the sympathetic nervous system and induce adipose tissue thermogenesis.

In UCP1 knockout (KO) mice, a model that lacks classical, UCP1-mediated BAT thermogenesis $(45,46)$, BAT becomes a potential source of circulating FGF21 upon long-term cold exposure. Gene expression as well as ex vivo tissue secretion assays confirm BAT but exclude muscle, WAT, and liver as sources of circulating FGF21 in these mice (13). Interestingly, this study could not confirm the previous observations on the release of FGF21 from BAT in WT mice (27), which were exposed to long-term cold. It has been frequently speculated that other heat sources (e.g., creatine-driven substrate cycling and PM20D1-regulated mitochondrial uncoupling) are alternatively activated to protect the body temperature $(47,48)$, possibly in other tissue sites such as subcutaneous WAT (sWAT). Consistent with the literature that claims the induction of browning by
FGF21 $(8,9)$, pronounced browning features in sWAT of UCP1KO mice, but not in WT mice, were observed (13). Thus, the significant release of FGF21 from non-functional BAT suggests the possibility of an endocrine crosstalk between BAT and other tissues to coordinate a systemic adaptive thermogenesis response in UCP1-KO mice.

To consolidate FGF21 dependency, UCP1-FGF21 double knockout (dKO) mice were created and characterized (14). Unexpectedly, the dKO mice displayed identical energy expenditure, browning of WAT, and defense of body temperature during long-term cold exposure as their single knockout, UCP1$\mathrm{KO}$, counterparts. This observation strongly suggests that the increases of FGF21 serum levels in UCP1-KO mice have no major impact on thermoregulatory capacity. Thus, one can highlight that FGF21 per se is not required for the defense of body temperature despite a strong induction of 
FGF21 in various adipose tissue depots during prolonged cold exposure (14).

\section{LIVER AS THE SOURCE FOR CIRCULATING FGF21}

The contribution of different tissues to circulating FGF21 in cold-induced thermogenesis was further dissected in a study that used adipose- and liver-specific knockout mouse models and cold exposure ranging from $1 \mathrm{~h}$ up to 6 days (40). Interestingly, the authors did not observe an increase in circulating FGF21 levels and therefore excluded an endocrine role for FGF21. In line with other studies (Figure 1), no increase of Fgf21 mRNA in the liver was detected upon cold exposure, and the adult liver-specific FGF21-KO mice did not show impairment in thermoregulation upon cold exposure. However, Fgf21 mRNA and protein are highly cold-induced in both BAT and WAT. Furthermore, the adipose tissue-specific FGF21-KO mice show reduced body temperature and recruitment of beige adipocytes in the early phase of cold exposure (40). This impairment of cold-induced adaptive thermogenesis suggests an autocrine thermoregulatory role of FGF21 in WAT and proposes the induction of beige adipocytes as an active player in thermogenesis.

Strongly opposing these results are the data of Ameka et al. (35). While both studies excluded BAT as a source of FGF21 upon cold exposure, here the authors highlight the liver as the source of circulating FGF21 in response to short-term cold exposure. In direct contrast to Huang et al. (40), the liver-specific FGF21-KO mice display decreased body temperatures upon short-term cold exposure, whereas the adipose-specific FGF21-KO mice do not. A liver FGF21-brain-BAT axis was highlighted by showing reduced sympathetic nerve activity to BAT in liver-specific FGF21-KO mice as well as in WT mice with pharmacologically inhibited FGF21 signaling in the brain (35).

An explanation for the study differences on the adipose tissue mouse model may reside in the use of the Cre mouse model. While Ameka et al. used the adiponectin-Cre mouse, Huang et al. used the aP2-Cre transgenic mouse, which expresses Cre recombinase not exclusively in adipose tissue (17). However, the differences found in the liver-specific $\mathrm{KO}$ mouse model remain puzzling.

\section{IS THERE AN AUTO-PARACRINE ROLE OF THERMOGENIC ADIPOSE FGF21 UPON COLD EXPOSURE?}

A general theme that crystalizes from nearly all published data is the induction of Fgf21 mRNA in BAT upon cold exposure (Figure 1), indicating a possible auto- paracrine role of FGF21 when the circulating levels remain unchanged. The inducing signaling cascade for $\mathrm{Fgf2} 1$ expression is almost identical as that found for UCP1 regulation: cyclic-AMP mediates the activation of protein kinase A and p38 MAPK, which activates transcription factor 2 for transactivation of the Ucp1 and Fgf21 gene promoters $(9,27,49)$, suggesting that adipose FGF21 is a downstream effector of sympathetic nerve activation. Surprisingly, however, the studies showing decreased body temperatures during cold exposure of FGF21-KO mice, including global and liver- and adipose-tissue specific knockouts, did not detect impairment of BAT thermogenic gene expression after cold exposure compared to WT mice $(9,35,40)$. Furthermore, no differences in UCP1 protein content, adipose morphology, or mitochondrial content were seen (40), suggesting that BAT is not the main driver for body temperature reductions in FGF21-KO mice. Two of these three studies, which do not detect any increase in circulating FGF21, instead found reduced thermogenic gene expression in WAT of FGF21-KO mice $(9,40)$, lower UCP1 protein levels, and less beige fat cells and mitochondrial content (40). These findings, once more, strongly support the auto-paracrine control of FGF21 over the "browning" of WAT, which in turn may contribute to thermogenesis.

During long-term cold exposure, however, no differences in thermogenic gene and protein expression, as well as in adipocyte morphology, were found in the BAT and sWAT of FGF21$\mathrm{KO}$ and WT mice (14). The interesting differences in BAT morphology between UCP1-KO and UCP1-FGF21 dKO mice, measured as a drastically reduced number of lipid droplets in the double-knockout mice, are so far unexplored. The comparison of global BAT transcriptomes in this study revealed FGF21 as one of the top regulated genes, followed by genes involved in the feedback regulation of FGF21 signaling (e.g., Dusp 4 and Spry4). These observations strongly suggest a bioactivity of endogenous FGF21 in vivo and may be interpreted as autoparacrine effects of supra-stimulated FGF21 function in UCP1KO mice, possibly related to lipid metabolism. Notably, the UCP1-KO mice show reduced survival rates when weaned and raised at $21^{\circ} \mathrm{C}$, which represents a temperature of moderate cold stress for mice, thereby highlighting the important role of UCP1 in thermoregulation. In contrast, the homozygous FGF21-KO mice, weaned and raised at $21^{\circ} \mathrm{C}$, do not show reduced survival rates or reduced body weight compared to their WT littermates (50, 51), thereby excluding a major role of FGF21 on the protection of body temperature during early life development.

\section{THE IMPACT OF DIET AND MILD COLD-INDUCED ENDOGENOUS FGF21 ON THERMOREGULATION}

Protein restriction in food is a potent inducer of FGF21 secretion from the liver into the circulation $(52,53)$. Alemán et al. (43) studied the interaction of temperature effects and the amount of dietary protein on thermogenic adipose tissue in rats (43). As expected, a low-protein diet led to an increase in liver Fgf21 expression and circulating FGF21, as well as to an increase in oxygen consumption rates at 23 and $4^{\circ} \mathrm{C}$, compared to an adequate-protein-content diet. Interestingly, an increase of UCP1 protein concentration was not seen in BAT but in sWAT of low-protein-fed rats kept at 23 and $4^{\circ} \mathrm{C}$. The authors speculated that low-protein diets stimulate energy expenditure via FGF21induced UCP1 protein expression in WAT. In line with this is the induction of $U c p 1$ gene expression only in sWAT, and not in BAT or epididymal WAT with low-protein diets, which disappears 
in liver-specific FGF21-KO mice (54). Moreover, no increase in energy expenditure was seen in UCP1-KO mice after lowprotein-diet feeding (37). In this study, it was further investigated whether the animals with high circulating FGF21 can cope better, with an acute cold stimulus, during low-protein-diet feeding. The increase of endogenous FGF21 levels in WT mice fed a low protein diet, however, had no effect on the acute thermogenic responses to cold, measured as body temperature (37). Therefore, we may conclude that albeit the increased circulating liverderived FGF21 levels induce Ucp1 gene expression in sWAT, this is not required for physiological protection from acute cold stress.

As mentioned previously, neither UCP1 nor FGF21 is required during adulthood to defend the body temperature from long-term cold exposure (14). It seems that an ambient temperature of $5^{\circ} \mathrm{C}$ for several weeks overrules FGF21 action, leading to FGF21-independent browning of WAT in UCP1-KO mice. Surprisingly, some of our newest data highlight mild coldinduced endogenous FGF21 as the primary metabolic regulator of obesity resistance, possibly mediated via WAT browning in UCP1-KO mice (55). How could the contradiction of the impact of FGF21 on browning of WAT between these studies be explained? There are two important differences in the study setup. In the most recent study, UCP1-KO mice were transferred from $30^{\circ} \mathrm{C}$ to mild cold $\left(23^{\circ} \mathrm{C}\right)$ instead of $4^{\circ} \mathrm{C}$ and the diet was switched from chow to high-fat diet. While mild cold exposure is essential to trigger FGF21 release in UCP1-KO mice, FGF21 only unfolds its anti-obesity effect in combination with overnutrition in the form of high-fat diets. This rationale is coherent with the pharmacology of exogenous FGF21, which does not reduce body weight in lean mice, but only in obese mice, and partly requires UCP1-independent thermogenesis for its beneficial metabolic effects $(6,56)$. This hypothesis is further strengthened by the requirement of increased endogenous FGF21 for the protection from HFD-induced body weight gain in different other mouse models $(57,58)$.

\section{SUMMARY AND CONCLUSION}

Ever since endogenous FGF21 has been associated to the expression of thermogenic genes in BAT of neonatal pups, researchers have been investigating FGF21's role for survival

\section{REFERENCES}

1. Cannon B, Nedergaard J. Brown adipose tissue: function and physiological significance. Physiol Rev. (2004) 84:277-359. doi: 10.1152/physrev.00015.2003

2. Nicholls DG, Locke RM. Thermogenic mechanisms in brown fat. Physiol Rev. (1984) 64:1-64. doi: 10.1152/physrev.1984.64.1.1

3. Coskun T, Bina HA, Schneider MA, Dunbar JD, Hu CC, Chen Y, et al. Fibroblast growth factor 21 corrects obesity in mice. Endocrinology. (2008) 149:6018-27. doi: 10.1210/en.2008-0816

4. Gaich G, Chien JY, Fu H, Glass LC, Deeg MA, Holland WL, et al. The effects of LY2405319, an FGF21 analog, in obese human subjects with type 2 diabetes. Cell Metab. (2013) 18:333-40. doi: 10.1016/j.cmet.2013.08.005

5. Talukdar S, Zhou Y, Li D, Rossulek M, Dong J, Somayaji V, et al. A longacting FGF21 molecule, PF-05231023, decreases body weight and improves in the cold. Unfortunately, the results are, to some extent, contradictory. On one hand, observations suggest higher circulating FGF21 levels upon cold exposure, while others report no changes or even decreased levels. When analyzing the studies that report increased levels, two tissue sites emerge as potential secretors: one being BAT, the other being the liver. Despite using sophisticated methods such as arteriovenous differences in plasma FGF21 across tissues and tissue-specific FGF21-KO mouse models, some of the results remain opposing, thereby revealing no unambiguous picture. While these contradictions could highlight the complexity of endogenous FGF21 action, one may also conclude that there is no crucial role of endocrineacting FGF21 during cold exposure. Common in all studies is the increase of Fgf21 mRNA expression in BAT during cold exposure, raising the possibility of auto- or paracrine signaling. However, the direct comparison of FGF21-KO mice and WT mice did not reveal cold-induced morphological or molecular differences in BAT compared to WT mice, despite a high induction of $F g f 21$ gene expression, suggesting a minor auto- paracrine role of FGF21 in BAT. The current literature instead predominantly supports an indirect as well as a direct impact of FGF21 on WAT in the early cold response, as well as during the combination of mild cold and nutritional composition. Given the sensitivity of FGF21 regulation to the nutritional composition of food and its pronounced effects on browning of WAT, the impact of FGF21 on thermoregulation during mild cold cannot be fully excluded. Further research is required to unravel the underlying molecular mechanisms that may be beneficial for the understanding of human obesity and metabolic diseases.

\section{AUTHOR CONTRIBUTIONS}

MK and SK wrote this review article in concert, read, and approved the submitted version. All authors contributed to the article and approved the submitted version.

\section{FUNDING}

SK was supported by the Swedish Research Council (2018-02150).

lipid profile in non-human primates and type 2 diabetic subjects. Cell Metab. (2016) 23:427-40. doi: 10.1016/j.cmet.2016.02.001

6. Véniant MM, Komorowski R, Chen P, Stanislaus S, Winters K, Hager $\mathrm{T}$, et al. Long-acting FGF21 has enhanced efficacy in diet-induced obese mice and in obese rhesus monkeys. Endocrinology. (2012) 153:4192-203. doi: 10.1210/en.2012-1211

7. Xu J, Lloyd DJ, Hale C, Stanislaus S, Chen M, Sivits G, et al. Fibroblast growth factor 21 reverses hepatic steatosis, increases energy expenditure, and improves insulin sensitivity in diet-induced obese mice. Diabetes. (2009) 58:250-9. doi: 10.2337/db08-0392

8. Emanuelli B, Vienberg SG, Smyth G, Cheng C, Stanford KI, Arumugam $\mathrm{M}$, et al. Interplay between FGF21 and insulin action in the liver regulates metabolism. J Clin Invest. (2014) 124:515-27. doi: 10.1172/JC 167353 
9. Fisher FM, Kleiner S, Douris N, Fox EC, Mepani RJ, Verdeguer F, et al. FGF21 regulates PGC-1 $\alpha$ and browning of white adipose tissues in adaptive thermogenesis. Genes Dev. (2012) 26:271-81. doi: 10.1101/gad.177857.111

10. Charles ED, Neuschwander-Tetri BA, Frias JP, Kundu S, Luo Y, Tirucherai GS, et al. Pegbelfermin (BMS-986036), PEGylated FGF21, in patients with obesity and type 2 diabetes: results from a randomized phase 2 study. Obesity. (2019) 27:41-9. doi: 10.1002/oby.22344

11. Sanyal A, Charles ED, Neuschwander-Tetri BA, Loomba R, Harrison SA, Abdelmalek MF, et al. Pegbelfermin (BMS-986036), a PEGylated fibroblast growth factor 21 analogue, in patients with non-alcoholic steatohepatitis: a randomised, double-blind, placebo-controlled, phase 2a trial. Lancet. (2018) 392:2705-17. doi: 10.1016/S0140-6736(18)31785-9

12. Verzijl CRC, Peppel IPVD, Struik D, Jonker JW. Pegbelfermin (BMS-986036): an investigational PEGylated fibroblast growth factor 21 analogue for the treatment of nonalcoholic steatohepatitis. Expert Opin Investig Drugs. (2020) 29:125-33. doi: 10.1080/13543784.2020.1708898

13. Keipert S, Kutschke M, Lamp D, Brachthäuser L, Neff F, Meyer CW, et al. Genetic disruption of uncoupling protein 1 in mice renders brown adipose tissue a significant source of FGF21 secretion. Mol Metab. (2015) 4:537-42. doi: 10.1016/j.molmet.2015.04.006

14. Keipert S, Kutschke M, Ost M, Schwarzmayr T, van Schothorst EM, Lamp D, et al. Long-term cold adaptation does not require FGF21 or UCP1. Cell Metab. (2017) 26:437-46.e5. doi: 10.1016/j.cmet.2017.07.016

15. Hanssen MJW, Broeders E, Samms RJ, Vosselman MJ, van der Lans AAJJ, Cheng CC, et al. Serum FGF21 levels are associated with brown adipose tissue activity in humans. Sci Rep. (2015) 5:10275. doi: 10.1038/srep10275

16. Lee P, Linderman JD, Smith S, Brychta RJ, Wang J, Idelson C, et al. Irisin and FGF21 are cold-induced endocrine activators of brown fat function in humans. Cell Metab. (2014) 19:302-9. doi: 10.1016/j.cmet.2013.12.017

17. Lee P, Brychta RJ, Linderman J, Smith S, Chen KY, Celi FS. Mild cold exposure modulates fibroblast growth factor 21 (FGF21) diurnal rhythm in humans: relationship between FGF21 levels, lipolysis, and cold-induced thermogenesis. J Clin Endocrinol Metab. (2013) 98:E98-102. doi: 10.1210/jc.2012-3107

18. Fisher FM, Maratos-Flier E. Understanding the physiology of FGF21. Annu Rev Physiol. (2016) 78:223-41. doi: 10.1146/annurev-physiol-021115-105339

19. Itoh N. Hormone-like (endocrine) Fgfs: their evolutionary history and roles in development, metabolism, and disease. Cell Tissue Res. (2010) 342:1-11. doi: 10.1007/s00441-010-1024-2

20. Adams AC, Cheng CC, Coskun T, Kharitonenkov A. FGF21 requires $\beta$ klotho to act in vivo. PLoS ONE. (2012) 7:e49977. doi: 10.1371/journal.pone.0049977

21. Kharitonenkov A, Dunbar JD, Bina HA, Bright S, Moyers JS, Zhang C, et al. FGF-21/FGF-21 receptor interaction and activation is determined by $\beta$ Klotho. J Cell Physiol. (2008) 215:1-7. doi: 10.1002/jcp.21357

22. Kurosu H, Choi M, Ogawa Y, Dickson AS, Goetz R, Eliseenkova AV, et al. Tissue-specific expression of betaKlotho and fibroblast growth factor (FGF) receptor isoforms determines metabolic activity of FGF19 and FGF21. J Biol Chem. (2007) 282:26687-95. doi: 10.1074/jbc.M704165200

23. Ogawa Y, Kurosu H, Yamamoto M, Nandi A, Rosenblatt KP, Goetz R, et al. BetaKlotho is required for metabolic activity of fibroblast growth factor 21 . Proc Natl Acad Sci USA. (2007) 104:7432-7. doi: 10.1073/pnas.0701600104

24. Nishimura T, Nakatake Y, Konishi M, Itoh N. Identification of a novel Fgf, Fgf-21, preferentially expressed in the liver. Biochim Biophys Acta. (2000) 1492:203-6. doi: 10.1016/S0167-4781(00)00067-1

25. Coate KC, Hernandez G, Thorne CA, Sun S, Le TDV, Vale K, et al. FGF21 is an exocrine pancreas secretagogue. Cell Metab. (2017) 25:472-80. doi: 10.1016/j.cmet.2016.12.004

26. Keipert S, Ost M, Johann K, Imber F, Jastroch M, van Schothorst EM, et al. Skeletal muscle mitochondrial uncoupling drives endocrine cross-talk through the induction of FGF21 as a myokine. Am J Physiol Endocrinol Metab. (2014) 306:E469-482. doi: 10.1152/ajpendo.00330.2013

27. Hondares E, Iglesias R, Giralt A, Gonzalez FJ, Giralt M, Mampel $\mathrm{T}$, et al. Thermogenic activation induces FGF21 expression and release in brown adipose tissue. J Biol Chem. (2011) 286:12983-90. doi: 10.1074/jbc.M110.215889

28. BonDurant LD, Ameka M, Naber MC, Markan KR, Idiga SO, Acevedo $\mathrm{MR}$, et al. FGF21 regulates metabolism through adipose-dependent and -independent mechanisms. Cell Metab. (2017) 25:935-944.e4. doi: 10.1016/j.cmet.2017.03.005
29. Bookout AL, de Groot MHM, Owen BM, Lee S, Gautron L, Lawrence HL, et al. FGF21 regulates metabolism and circadian behavior by acting on the nervous system. Nat Med. (2013) 19:1147-52. doi: 10.1038/nm.3249

30. Song P, Zechner C, Hernandez G, Cánovas J, Xie Y, Sondhi V, et al. The hormone FGF21 stimulates water drinking in response to ketogenic diet and alcohol. Cell Metab. (2018) 27:1338-1347.e4. doi: 10.1016/j.cmet.2018.04.001

31. Owen BM, Ding X, Morgan DA, Coate KC, Bookout AL, Rahmouni K, et al. FGF21 acts centrally to induce sympathetic nerve activity, energy expenditure, and weight loss. Cell Metab. (2014) 20:670-7. doi: 10.1016/j.cmet.2014.07.012

32. Douris N, Stevanovic DM, Fisher FM, Cisu TI, Chee MJ, Nguyen NL, et al. Central fibroblast growth factor 21 browns white fat via sympathetic action in male mice. Endocrinology. (2015) 156:2470-81. doi: 10.1210/en.2014-2001

33. Chartoumpekis DV, Habeos IG, Ziros PG, Psyrogiannis AI, Kyriazopoulou VE, Papavassiliou AG. Brown adipose tissue responds to cold and adrenergic stimulation by induction of FGF21. Mol Med Camb Mass. (2011) 17:736-40. doi: 10.2119/molmed.2011.00075

34. Hondares E, Rosell M, Gonzalez FJ, Giralt M, Iglesias R, Villarroya F. Hepatic FGF21 expression is induced at birth via PPAR $\alpha$ in response to milk intake and contributes to thermogenic activation of neonatal brown fat. Cell Metab. (2010) 11:206-12. doi: 10.1016/j.cmet.2010.02.001

35. Ameka M, Markan KR, Morgan DA, BonDurant LD, Idiga SO, Naber MC, et al. Liver derived FGF21 maintains core body temperature during acute cold exposure. Sci Rep. (2019) 9:630. doi: 10.1038/s41598-018-37198-y

36. Bal NC, Maurya SK, Pani S, Sethy C, Banerjee A, Das S, et al. Mild cold induced thermogenesis: are BAT and skeletal muscle synergistic partners? Biosci Rep. (2017) 37:BSR20171087. doi: 10.1042/BSR20171087

37. Hill CM, Laeger T, Albarado DC, McDougal DH, Berthoud H-R, Münzberg $\mathrm{H}$, et al. Low protein-induced increases in FGF21 drive UCP1-dependent metabolic but not thermoregulatory endpoints. Sci Rep. (2017) 7:8209. doi: 10.1038/s41598-017-07498-w

38. Piao Z, Zhai B, Jiang X, Dong M, Yan C, Lin J, et al. Reduced adiposity by compensatory WAT browning upon iBAT removal in mice. Biochem Biophys Res Commun. (2018) 501:807-13. doi: 10.1016/j.bbrc.2018.05.089

39. Challa TD, Dapito DH, Kulenkampff E, Kiehlmann E, Moser C, Straub L, et al. A genetic model to study the contribution of brown and brite adipocytes to metabolism. Cell Rep. (2020) 30:3424-3433.e4. doi: 10.1016/j.celrep.2020.02.055

40. Huang Z, Zhong L, Lee JTH, Zhang J, Wu D, Geng L, et al. The FGF21CCL11 axis mediates beiging of white adipose tissues by coupling sympathetic nervous system to type 2 immunity. Cell Metab. (2017) 26:493-508.e4. doi: 10.1016/j.cmet.2017.08.003

41. Vázquez P, Hernández-Sánchez C, Escalona-Garrido C, Pereira L, Contreras $\mathrm{C}$, López $\mathrm{M}$, et al. Increased FGF21 in brown adipose tissue of tyrosine hydroxylase heterozygous mice: implications for cold adaptation. J Lipid Res. (2018) 59:2308-20. doi: 10.1194/jlr.M085209

42. Flachs P, Adamcova K, Zouhar P, Marques C, Janovska P, Viegas I, et al. Induction of lipogenesis in white fat during cold exposure in mice: link to lean phenotype. Int J Obes. (2017) 41:997. doi: 10.1038/ijo. 2017.61

43. Alemán G, Castro AL, Vigil-Martínez A, Torre-Villalvazo I, DíazVillaseñor A, Noriega LG, et al. Interaction between the amount of dietary protein and the environmental temperature on the expression of browning markers in adipose tissue of rats. Genes Nutr. (2019) 14:19. doi: 10.1186/s12263-019-0642-x

44. Sepa-Kishi DM, Ceddia RB. Circulating fibroblast growth factor 21 is reduced, whereas its production is increased in a fat depotspecific manner in cold-acclimated rats. Adipocyte. (2018) 7:238-47. doi: 10.1080/21623945.2018.1504591

45. Enerbäck S, Jacobsson A, Simpson EM, Guerra C, Yamashita H, Harper ME, et al. Mice lacking mitochondrial uncoupling protein are cold-sensitive but not obese. Nature. (1997) 387:90-4. doi: 10.1038/387090a0

46. Golozoubova V, Cannon B, Nedergaard J. UCP1 is essential for adaptive adrenergic nonshivering thermogenesis. Am J Physiol Endocrinol Metab. (2006) 291:E350-7. doi: 10.1152/ajpendo.00387.2005

47. Kazak L, Chouchani ET, Jedrychowski MP, Erickson BK, Shinoda K, Cohen $\mathrm{P}$, et al. A creatine-driven substrate cycle enhances energy expenditure and thermogenesis in beige fat. Cell. (2015) 163:643-55. doi: $10.1016 /$ j.cell.2015.09.035 
48. Long JZ, Svensson KJ, Bateman LA, Lin H, Kamenecka T, Lokurkar IA, et al. The Secreted enzyme PM20D1 regulates lipidated amino acid uncouplers of mitochondria. Cell. (2016) 166:424-35. doi: 10.1016/j.cell.201 6.05.071

49. Cao W, Daniel KW, Robidoux J, Puigserver P, Medvedev AV, Bai X, et al. p38 mitogen-activated protein kinase is the central regulator of cyclic AMP-dependent transcription of the brown fat uncoupling protein 1 gene. Mol Cell Biol. (2004) 24:3057-67. doi: 10.1128/mcb.24.7.3057-30 67.2004

50. Hotta Y, Nakamura H, Konishi M, Murata Y, Takagi H, Matsumura S, et al. Fibroblast growth factor 21 regulates lipolysis in white adipose tissue but is not required for ketogenesis and triglyceride clearance in liver. Endocrinology. (2009) 150:4625-33. doi: 10.1210/en.2009-0119

51. Potthoff MJ, Inagaki T, Satapati S, Ding X, He T, Goetz R, et al. FGF21 induces PGC- $1 \alpha$ and regulates carbohydrate and fatty acid metabolism during the adaptive starvation response. Proc Natl Acad Sci USA. (2009) 106:10853-8. doi: 10.1073/pnas.0904187106

52. Laeger T, Henagan TM, Albarado DC, Redman LM, Bray GA, Noland RC, et al. FGF21 is an endocrine signal of protein restriction. J Clin Invest. (2014) 124:3913-22. doi: 10.1172/JCI74915

53. Maida A, Zota A, Sjøberg KA, Schumacher J, Sijmonsma TP, Pfenninger A, et al. A liver stress-endocrine nexus promotes metabolic integrity during dietary protein dilution. J Clin Invest. (2016) 126:3263-78. doi: 10.1172/JCI85946

54. Pérez-Martí A, Garcia-Guasch M, Tresserra-Rimbau A, Carrilho-DoRosário A, Estruch R, Salas-Salvadó J, et al. A low-protein diet induces body weight loss and browning of subcutaneous white adipose tissue through enhanced expression of hepatic fibroblast growth factor 21
(FGF21). Mol Nutr Food Res. (2017) 61:1600725. doi: 10.1002/mnfr.201 600725

55. Keipert S, Lutter D, Schroeder BO, Brandt D, Ståhlman M, Schwarzmayr $\mathrm{T}$, et al. Endogenous FGF21-signaling controls paradoxical obesity resistance of UCP1-deficient mice. Nat Commun. (2020) 11:624. doi: 10.1038/s41467-019-14069-2

56. Samms RJ, Smith DP, Cheng CC, Antonellis PP, Perfield JW, Kharitonenkov A, et al. Discrete aspects of FGF21 in vivo pharmacology do not require UCP1. Cell Rep. (2015) 11:991-9. doi: 10.1016/j.celrep.2015.04.046

57. Lynch L, Hogan AE, Duquette D, Lester C, Banks A, LeClair K, et al. iNKT cells induce FGF21 for thermogenesis and are required for maximal weight loss in GLP1 therapy. Cell Metab. (2016) 24:510-9. doi: 10.1016/j.cmet.2016.08.003

58. Wall CE, Whyte J, Suh JM, Fan W, Collins B, Liddle C, et al. Highfat diet and FGF21 cooperatively promote aerobic thermogenesis in mtDNA mutator mice. Proc Natl Acad Sci USA. (2015) 112:8714-9. doi: $10.1073 /$ pnas. 1509930112

Conflict of Interest: The authors declare that the research was conducted in the absence of any commercial or financial relationships that could be construed as a potential conflict of interest.

Copyright (C) 2020 Klein Hazebroek and Keipert. This is an open-access article distributed under the terms of the Creative Commons Attribution License (CC BY). The use, distribution or reproduction in other forums is permitted, provided the original author(s) and the copyright owner(s) are credited and that the original publication in this journal is cited, in accordance with accepted academic practice. No use, distribution or reproduction is permitted which does not comply with these terms. 